\title{
Current State of ICT in Healthcare Delivery in Developing Countries
}

\author{
https://doi.org/10.3991/ijoe.v15i08.10294 \\ Adebayo Omotosho ${ }^{(凶)}$, Peace Ayegba \\ Landmark University, Omu-Aran, Nigeria \\ bayotosho@gmail.com \\ Justice Emuoyibofarhe \\ Ladoke Akintola University of Technology, Ogbomoso, Nigeria \\ Christoph Meinel \\ University of Potsdam, Potsdam, Germany
}

\begin{abstract}
Electronic health is one of the most popular applications of information and communication technologies and it has contributed immensely to health delivery through the provision of quality health service and ubiquitous access at a lower cost. Even though this mode of health service is increasingly becoming known or used in developing nations, these countries are faced with a myriad of challenges when implementing and deploying e-health services on both small and large scale. It is estimated that the Africa population alone carries the highest percentage of the world's global diseases despite its certain level of e-health adoption. This paper aims at analyzing the progress so far and the current state of e-health in developing countries, particularly Africa, and proposes a framework for further improvement.
\end{abstract}

Keywords -E-health, developing countries, framework, ICT, healthcare.

\section{$1 \quad$ Introduction}

Individuals in poor and developing countries have the least access to health services due to low financial resources, lack of infrastructure and other barriers in accessing the needed services $[1,2]$. In addition, the dearth of competent health care professionals and low health education has contributed to the need for a shift in paradigm and innovative solutions in health workforce development. The popularity and growth of the Internet and mobile wireless technologies have assisted in changing the face of healthcare delivery and health education for health professionals in many countries. There has been an increasing number of developed and developing countries with e-health strategies, and as of 2015, Bangladesh, Paraguay, Qatar, and Rwanda were the most recent group of countries with official adoption of e-health strategies out of the 73 countries with e-health adoption [3]. 
However, the income of the populace generally affects individuals' access to health care services, and in the past, it has been recorded that only $12 \%$ of low income and middle-income countries (LMIC) spend on health care services [4]. About 50\%, 30\% and $14 \%$ of individuals in LMIC, middle-income countries and high-income countries respectively pay for healthcare services themselves. According to the World Bank income group, with regards to the source of funding of e-health; public, individual donor, public-private partnership and private were identified as the main sources. However, in the United States alone, between 1990 and 2007, the health assistance funds have grown from $\$ 5.6$ billion to $\$ 21.8$ billion [5]. It is estimated that Africa which has $11 \%$ of the entire world's population carries $22 \%$ of the global diseases [6]. In South Africa, state healthcare is provided to about 40 million people (82\%' of the population) with about 9500 doctors, and private healthcare with 25,000 doctors serve 8.5 million people. Tanzania has a doctor-patient ratio of 1:20000 and Kenya, a doctor-patient ratio of 1:16,000. In Nigeria with over 150 million people, a study carried out by Nigeria Medical Association revealed a doctor-patient ratio of 1:4250 [7, 8].

Developing countries population is also among the highest in the world and the demand for quality, affordable and accessible healthcare is high. Without the integration of technology into existing infrastructure, it may be impossible to meet the healthcare need of the populace. Information and Communication Technologies (ICT) have been described as a general-purpose technology (GPT) that can impact growth and transform countries over a prolonged period of time, and like every other GPT such as steam engine and electricity, it is characterized by pervasiveness, improvement, and innovation [9]. In addition, ICT produces two other effects - network and knowledge enrichment. A country intending to benefits from ICT revolution must have a productive digital strategy. One of the many benefits of ICT enabled health system is the ability to decrease patient's data collection cost by about $71 \%$ [6]. Ehealth is generally defined as the use of ICT for health, popular forms of e-health include telemedicine, telehealth, m-Health, consumer health informatics, electronic health records, healthcare information system [10,3]. E-health is becoming recognizable in Africa and a survey report by [11] indicated that South Africa, Kenya, and Ghana have the most e-health and health informatics strategies implemented with Kenya leading the market in digital health. Ethiopia is also seen to have one of the most effective healthcare systems with health extension programs, the utilization of telemedicine and mobile applications for promoting health care services.

For instance, in Africa, patients' anamneses are mostly fragmented, disjointed and distributed among several healthcare givers platforms which may be public or private $[12,13,14,15]$. This, however, constitutes a problem that limits completeness, sharing and accessibility of information, most especially with public hospitals which are generally non-ICT compliant. [16] Supported this claim in their report - that the use of ICT is growing at a faster pace in private health organizations in developing countries than in public health organizations. Public healthcare in rural areas faces a shortage of professional, patient's noncompliance, and potential fraud which could be alleviated with the widespread adoption of ICT in health care. E-health education and awareness are also key factors, government and stakeholders must engage in pilot ehealth projects that could provide more evidence to support their investment and pro- 
mote widespread adoption. Lastly, e-health systems are capable of motivating and improving patient's engagement in their health care, and if e-health systems are designed with the local context, target users' needs and preference in mind, rather than an isolated solution, e-health technology will add value to the patient and treatment [17]. The paper aims at analyzing progress so far and the current state of e-health in developing countries particularly Africa and propose a framework for further improvement.

\section{Selected Existing Studies on E-health in Developing Countries Chronologically Reviewed From 2010 to 2018}

[18] Performed a qualitative and quantitative survey on the role of ICT in health care services for developing countries. In their article search criteria, 'e-health' was used interchangeably with the term 'health information technology'. The search was carried out in October 2009, using articles from Medline, Embase, Web of Science, LILACS, Google Scholar search, Rhino, and Social Sci Citation index databases. In the exploration, a total of 2043 citations and 55 articles (15 qualitative and 40 quantitative) were used. Their evaluation results suggested the use of more robust e-health practices in developing countries. It was also noted that personal digital assistants and mobile devices boost up the efficiency of e-health practices. [19] Performed an extensive review of existing e-health frameworks used in the development and deployment of e-health technologies so as to identify aspects of their use that influence their success. The database sources used were PubMed, Science Direct, Picarta, Google Scholar, and Web of Knowledge, and 44 journals were selected for the review out of the 60 articles acquired. Results indicated that the Web 2.0 technologies which demand a more stakeholder-driven approach are outside the current framework's scope. Their results were then used to propose a holistic approach in the development of ehealth technologies which combines health technology theories and business models that act as a road map in the impact of e-health technologies.

Telemedicine is another widely favored form of e-health and it involves the medical information interchange between different parties situated at separate geographical areas through the use of a telecommunication link. The challenges in the implementation of the first telemedicine program in Ethiopia that ran between 2004 and 2006 were analyzed by [20]. $85 \%$ of Ethiopia's population live in remote areas and do not have access to adequate health care facilities. The first trial was carried out in 10 health care sites where a telemedicine software from wireless distribution system technologies was implemented. The software had a lot of technical difficulties and Telemed-ETH, another telemedicine software was developed as an improvement. Results of the interviews from participants showed about $70 \%$ faced connectivity problems and $61 \%$ reported that the system was disorganized. Also, it was found that $25 \%$ of the participants indicated interest in scaling up telemedicine in their universities. It was concluded that e-health and telemedicine could contribute immensely to the growth of health coverage in Ethiopia. The project was funded by the International 
Telecommunication Union-United Nations Economic Commission for Africa and infodev.

[21] Published a work that described the level of satisfaction of Brazilian physicians using an implemented EHR. A cross-sectional questionnaire survey was carried out with a total of 111 subjects, although only 99 physicians responded. $81.4 \%$ of the respondents believed the EHR response time was not as fast as expected, $86.7 \%$ reported that the system had technical failures and $35.1 \%$ complained about insufficient computers at their health clinics. The final result showed that only $2 \%$ of the respondents were well satisfied with the EHR, 50.5\% were partly satisfied and $47.5 \%$ were dissatisfied. In addition, in their conclusion, it was documented that structural issues and lack of classical functions like clinical reminders were some challenges faced by the EHR system, among other complaints. [22] carried out a survey on the adoption of the electronic clinical decision support system (eCDSS) for maternal care in Tanzania and Ghana between 2011 and 2013. A total of 282 health workers participated in the survey and the majority of them responded positively. $71 \%$ of 3,798 patients and $59 \%$ of 24, 204 patients were managed in Tanzania and Ghana respectively by the eCDSS over the space of two years. It was concluded that the system was a viable tool to be implemented in rural areas as it is user-friendly and useful.

[23] Performed a review on the progress of mHealth - the use of mobile device technology for health-related purposes - in Sub-Saharan Africa. The study was restricted to articles published within a 10-year period before March 16, 2013, with the search keyword "mHealth" in PubMed. From a total of the 21 articles reviewed, it was found that medication adherence, health worker communication, emergency, and disaster response, as well as health education, were some of the improvements made by mHealth in Sub-Saharan Africa. It was also concluded that more research regarding the cost-effectiveness of mHealth and e-health technologies in Africa is still required. [24] carried out a methodical review on the impact of e-health through a literature search in PubMed, MEDLINE, EBSCO Academic Complete, ScienceDirect, IEEE, AIS e-library, CINAHL, and the ACM databases, with no restriction on the search date. Out of the 265 articles obtained, only 13 articles met the inclusion criteria - a qualitative empirical study in the utilization and influence of e-health technology for community health facilities (CHF) in a developing country. The method used in the majority of these 13 articles were surveys done in Africa. In their finding, the Electronic Medical Record system was the most widely recognized e-health technology tool identified that focused on the quality of healthcare. The limited number of articles included suggested a low rate of diffusion, in developing countries, of e-health in community-based facilities. Results of their review also showed that the majority of research focuses on the effectiveness of these technologies and little on equity and efficiency.

[25] Performed a cross-sectional study to investigate users' attitudes to the use of an interactive voice system (IVR) in seeking healthcare services in Ghana. Forty participants were involved in the focus group discussions (21 female and 19 male) with an age range between 18 and 59 years. Most of the participants showed interest in the use of the IVR system for health care services especially with the general use of mobile phones and a toll-free number for the system was recommended. [26] examined 
the factors that influence the adoption and utilization of e-health facilities in Bangladesh, South East Asia. A survey of patients was carried out with a questionnaire where the average age of the participants is above 30 years of age. The study examined patients' behavioral intent in the adoption of e-health using an extended technology acceptance model (TAM). Results showed that the perceived ease of use (PEU), perceived usefulness and trust are important prerequisites for patients' adoption of ehealth, whereas privacy has no effect on the use of e-health in Bangladesh. It was also found that gender strongly influences the use of e-health with a stronger PEU influence in males.

Telemedicine, a subset of e-health, is the least likely to be administered in developing countries due to poor connectivity and inadequate infrastructure according to [27], who reviewed 228 articles in Scopus database to reveal current telemedicine activities in Africa. It was concluded that tele-education is the most widely recognized and effective application e-health in Africa, and therefore telemedicine has great potentials to thrive in Africa. [28] focused on the benefits and challenges in the implementation of e-health systems for perinatal and maternal health care in Tanzania. Mobile teleconsultation platforms, audio teleconferencing model and online e-learning systems were implemented in ten upgraded health care centers, including one regional hospital, and four rural district hospitals. Thirty-three teleconferences were held and there were forty healthcare participants, including assistant medical officers and midwives. A total of thirty-eight emergency teleconsultations were also attended to by consultant obstetricians in 2015 and $87 \%$ of the patients were successfully managed. On the e-learning platform, out of forty registered users, twenty users were interviewed after six months of participation and $65 \%$ found the system easy to use, $15 \%$ found it difficult and $20 \%$ were neutral. These results indicate great potentials for the progress of e-health systems in Tanzania. Their study, however, does not adequately evaluate the impact of these platforms on health outcomes.

[29] Examined the forms of e-health and information system theories to understand the sustainability and implementation of e-health particularly in developing countries. Some of the theories include the actor-network theory (ANT), technology acceptance model (TAM) and the technology organization and environmental framework (TOE). Based on their findings, some of the issues that affect the development of e-health identified include, e-health standards, ICT and health policies, ICT competence, elegislation, and e-health infrastructure. [30] Examined the diffusion of telemedicine practices in Ghana, and like any other developing countries in Africa, health centers and facilities in Ghana are not enough to be accessible by everyone. However, ehealth in Ghana has shown great promises with the recent development of the Novartis telemedicine project in Bonasso. The foundation made provision for mobile devices for the propagation of telemedicine and teleconsultation services to medical personnel. Eight cases of e-health and telemedicine practices in Ghana were outlined and these cases showed the use of telemedicine, e-health, teleradiology, teledermatology, teleconsultation, telecommunication, telemedicine and prenatal care implementation in Ghana. Using e-health systems, it was also shown that the new HIV infections in Ghana reduced by 53\% from $2001-2014$. This result shows that with adequate sup- 
port from the government and funding, telemedicine will influence healthcare positively in Ghana and other developing countries.

[31] Investigated the ICT performance of the 10-member states of the Association of Southeast Asian Nations (ASEAN) countries, comprising of developing countries and least developed countries of the world. It was found that ICT progress is not evenly distributed and the author proposed that monitoring of the progress of member countries on ICT digitization needs improvement. Another important finding showed that in order to measure the adoption of mobile technologies, mobile phones penetrations are a no longer meaningful indicator in this region. The obstacles in transitioning health systems in LMIC were identified in [32]. Based on a study of Bangladesh and China pluralistic health sectors with relatively underdeveloped institutional arrangements, it was reported that despite the significant economic differences between the countries, both countries have in common, high mobile phone adoption, excellent ICT sector and supportive government which has helped in their e-health strategies. The authors advocated for the support, contribution and influence of government and stakeholders in driving a successful ICT in health care to increase access to safe, effective, affordable health care to the poor. Factors responsible for ICT diffusion were also identified, these include time taken to build a partnership between private and public sectors and lack of a supportive regulatory environment.

[33] Presented a project called EXTEND which aims at addressing issues affecting the use of e-health tools in Nigeria. The protocols used for this project is mixedmethod - non-randomized cluster trial of the use of e-health tools. The project attempts to evaluate e-health applications in Kano, Ondo, and Abuja. Then two applications called the Video Training Application (VTR) and the Clinical patient application toolkit (CliniPAK) were successfully implemented between 2016 and 2017 in 126 primary health care facilities (PHC) in all three states. Health workers were also trained to make use of these applications. The project is said to comprise three phases, a baseline within 3 months, a 12-month midline assessment and end line evaluation in 24 months. The project though not yet completed is expected to generate new knowledge to improve the quality and efficiency of e-health systems. [34] Reviewed literature that explored the challenges of e-health in LMIC. Four African countries, Rwanda, Kenya, Malawi, and Uganda were explored in their study. Some of the challenges of e-health noted in this region include little participation in e-health development, lack of a formal standardization process, unregulated penetration of e-health systems and delayed e-health standardization efforts. Their results also showed that LMIC's participation in seven e-health standard development organizations is a low $23.3 \%$, hence the necessity to develop standards that meet every country's interoperability needs, especially in resource-constrained environments.

[35] Focused their study on e-health applications in the Middle East and North Africa. The paper relayed the importance of the Middle East and North African Health Informatics Association - an NGO that focuses on health informatics. Instances of ehealth implementations in major countries of this region were highlighted, In Egypt, several companies have implemented thriving e-health projects like mHealth and pharmacy management systems. In Jordan, an electronic medical record system called Hakeem has been implemented nationwide. In Morocco, the ministry of health tele- 
medicine initiatives is in progress. In Palestine, a project implemented between 2008 and 2013 procured the use of Avicenna, the first EHR system, though the system lacked interoperability. In Sudan, the first National Telemedicine Network was established in 2007. In Tunisia, there is the establishment of Tunisian Society for e-health and Telemedicine in 2000 whose purpose is to advance the development of digital health, and in the UAE, there is the implementation of electronic medical record adoption model as well as a tool to unify medical records. [36] Performed research similar to [26], but emphasized on rural end-users' acceptance of e-health in Bheramara subdistrict, Bangladesh. The authors pointed out the existence of a portable health clinic (PHC) service that has served about 41,240 rural patients in different remote locations.

In their methodology, a survey was performed between June and July 2016 with 292 rural participants. The results of their study showed that the social reference was the most significant influential variable followed by, attitude to the system, access to cell phones, then perceived the effectiveness of the system. [37] described the implementation of a new OpenMRS- based system called AfyaEHMS in Kenya. This system was implemented in 320 health facilities in Machakoscounty, Kenya. Some of the key challenges of the system discussed include, use of scalable infrastructure, stakeholder engagement, harnessing local talent in the development of the system, system integration, and large project scope.

There has also been a low diffusion of e-health systems in Zimbabwe according to [38] who performed a qualitative study on the factors affecting the implementation of e-health in their public hospitals. Semi-structured interviews were carried out from twenty medical doctors in three central and seven provincial hospitals.

These interviewed doctors had prior experiences using EHR, telemedicine and District hospital information systems (DHIS). Inadequate e-health infrastructures, lack of ICT skills by medical doctors, resistance to change and government policies were some of the factors revealed to be limiting e-health diffusion.

A three-way relation that exists between e-health, health care professionals and patients in Sub Saharan Africa was considered in [39] to ascertain whether patients' ehealth preference can influence health care professionals' decision to use technology in their clinical practice.

The interview was employed, as well as a Q-methodology with an adopted mixedmethodology approach that involves participants arranging 46 statements with respect to how they influenced their clinical practice. It was found that patients influence the clinical choice of health care professionals. Table 1 shows the state and visibility of different forms of e-health in some developing countries. 
Paper-Current State of ICT in Healthcare Delivery in Developing Countries

Table 1. Varieties of e-health application in developing countries

\begin{tabular}{|c|c|c|c|c|}
\hline Author & Country & E-health type & Specific E-health initiative & $\begin{array}{l}\text { E-health } \\
\text { Strategy }\end{array}$ \\
\hline [27] & South Africa & Telemedicine & $\begin{array}{l}\text { Video conferencing for e- } \\
\text { health }\end{array}$ & YES \\
\hline [40] & $\begin{array}{l}\text { Ghana, Rwanda, Kenya, } \\
\text { South Africa, Ghana, } \\
\text { Lesotho, Zimbabwe, } \\
\text { Uganda, Tanzania, } \\
\text { Mozambique }\end{array}$ & $\begin{array}{l}\text { Electronic medical } \\
\text { record (EMR) }\end{array}$ & OpenMRS & YES \\
\hline [21] & Brazil & EHR & Unspecified & YES \\
\hline [41] & Botswana & mHealth & Not specified & \\
\hline [22] & Tanzania, Ghana & \begin{tabular}{|l} 
Electronic clinical \\
decision support \\
system
\end{tabular} & eCDSS & YES \\
\hline$[42]$ & Morocco, Tunisia & $\begin{array}{l}\text { Health Management } \\
\text { Information System } \\
\text { (HMIS), } \\
\text { Electronic Medical } \\
\text { Record, } \\
\text { Hospital Infor- } \\
\text { mation System, } \\
\text { Teleservices }\end{array}$ & Unspecified & YES \\
\hline$[25,30]$ & Ghana & $\begin{array}{l}\text { mHealth, Telemedi- } \\
\text { cine }\end{array}$ & $\begin{array}{l}\text { Mobile interactive voice } \\
\text { response system (IVR) }\end{array}$ & YES \\
\hline [43] & Uganda & $\begin{array}{l}\text { mHealth, Electronic } \\
\text { Medical Record }\end{array}$ & $\begin{array}{l}\text { Matibabu application, mTrack, } \\
\text { District health management } \\
\text { system (DHIS2) }\end{array}$ & YES \\
\hline$[33,30]$ & Nigeria & $\begin{array}{l}\text { Electronic Health } \\
\text { Record, Telemedi- } \\
\text { cine }\end{array}$ & $\begin{array}{l}\text { Clinical patient administrative } \\
\text { kit (Clinipak), Video Training } \\
\text { application (VTR), } \\
\text { VSee telemedicine kit } \\
\text { (All-purpose medical infor- } \\
\text { mation system) } \\
\text { APMIS }\end{array}$ & NO \\
\hline$[20,44]$ & Ethiopia & $\begin{array}{l}\text { Telemedicine, } \\
\text { mHealth }\end{array}$ & $\begin{array}{l}\text { Telemed-ETH, Project Orchid } \\
\text { mHealth platform }\end{array}$ & YES \\
\hline$[29,45,37]$ & Kenya & $\begin{array}{l}\text { EMR, EHR, Health } \\
\text { Information system, } \\
\text { Electronic health } \\
\text { management system } \\
\text { System }\end{array}$ & $\begin{array}{l}\text { DHIS2, KenyaEMR, Interna- } \\
\text { tional quality care health } \\
\text { management information } \\
\text { system (IQCHM), AfyaEHMS }\end{array}$ & YES \\
\hline [37] & $\begin{array}{l}\text { South Africa, Zambia, } \\
\text { Uganda, } \\
\text { Jamaica }\end{array}$ & $\begin{array}{l}\text { EMR, Electronic } \\
\text { Health Record }\end{array}$ & Bahmni, GnuHealth & YES \\
\hline [36] & Bangladesh & Telehealth & Portable Health Clinic (PHC) & YES \\
\hline
\end{tabular}

\section{Deduction and Proposed Framework}

Some of the major challenges of e-health in developing countries identified in this work include - lack of necessary infrastructure, theoretically designed intervention, 
low awareness, poor funding, unregulated penetration of e-health technologies, lack of formal standardization, lack of integrated and accessible health system, bureaucracy of the ministry of health on utilization of e-health, sustainability of health systems, lack of qualified personnel, lack of globally interconnected health system technologies, cost-benefit, and security and privacy. Based on the reviewed works, e-health visibility in Africa and other developing counties of the world is becoming noticeable, however, there are still multifarious hurdles to be crossed and framework to further the expansion is shown in Figure 1. Some of the important components of this framework are discussed.

\subsection{Funding}

Funds are required to adopt innovations locally, for testing, organizing meetings with potential users, to pay teams involved in the project and integrating these technologies in health operations. Most developing countries lack the necessary financial strength to properly fund and implement e-health strategies. Many healthcare innovators struggle to fund their innovations and proposed e-health technology especially during the structural implementation.

Nevertheless, the majority of health funds are from insurance packages, investments from private parties and other patients (or clients). However, besides providing special allocation for e-health financing in the national budget, the government can increase funding sources by partnering with local and international companies and bodies who have an interest in health.

Also, due to the high demand for standard quality of wellbeing, units can be created as arms of the government to take up this challenge. [46] Suggested several financing opportunities for e-health investment that involved mixed financing arrangements from public-private partnerships, private ICT vendors, public health vendors, public health service provider organizations (HPOs) as well as third-party payers. These investors are advised to invest in effective, comprehensive financing packages that include long term recurring expenses.

Some additional sources of funding in forms of donations and loans suggested by [47] include the World Bank, United Nations development programme (UNDP), African development bank (ADB), the World health organization (WHO), United States agency for international development (USAID), Islamic development bank (IDB), Japan international cooperation agency (JAICA) and individual organizations like the Gates Foundation. 


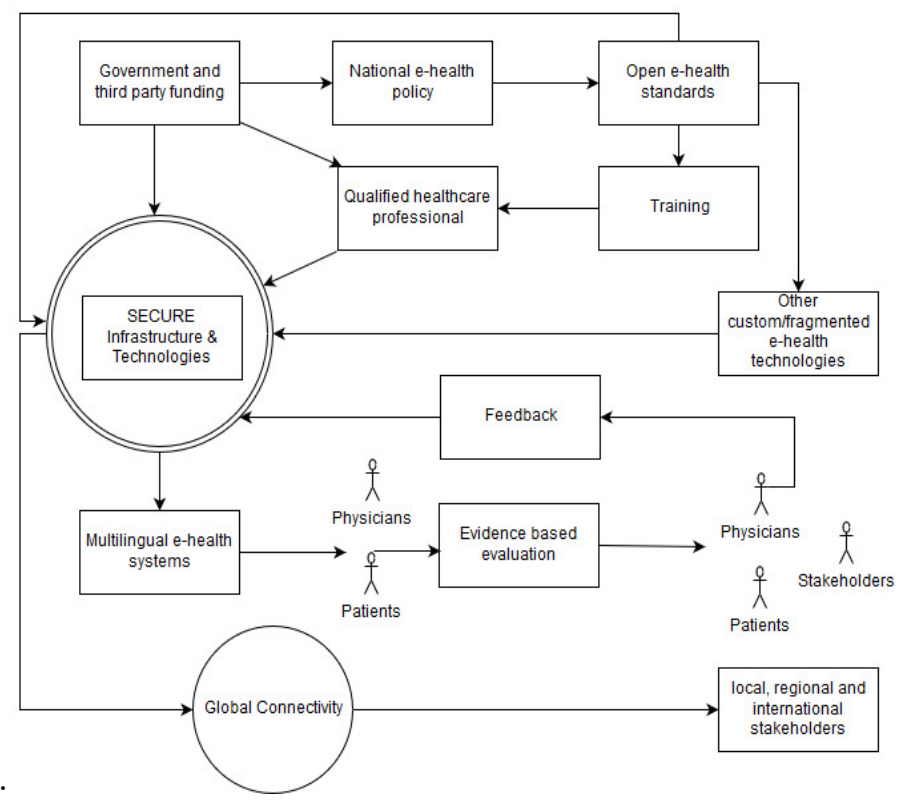

Fig. 1. A proposed framework for e-health sustainability

\subsection{Infrastructural facilities}

In the setup of e-health technologies, infrastructure - which are unevenly distributed - are major necessities in the success of e-health application. A convenient working environment, Internet facilities, and communication systems can help to improve the performance and productivity of health care workers using electronic facilities. A high percentage of people in developing countries live in rural areas and there are structural limitations in physically implementing e-health technologies. This implies that more basic facilities will be procured although, in the long run, the return on investment is expected to be high. Keeping in mind, that the hardware acquisition and maintenance in resource-constrained countries is very difficult and a few human resources are available to maintain these technologies, rather than starting from the scratch and incurring high setup cost, the scattered existing public and private innovative e-health facilities and solutions that are working can be upgraded and easily funded. Infrastructure can be donated and build operate and transfer (BOT) can be encouraged in order to ensure fast resources.

\subsection{Qualified E-health professional and training}

Work experience and training sessions in e-health is needed for integrating e-health initiatives into already existing healthcare services in developing countries. Since ehealth solutions are not at an advanced stage in the majority of these nations, healthcare professionals and their patients expect easy usage and navigation of health 
technologies in order to achieve the required functionality. In addition, complexity factors can occur when health professionals are unable to adequately master the system. Such complexities include speed, connectivity issues, unplanned downtime and the overall reliability of the system. Continued education on e-health inventions is therefore essential.

These training should be designed to equip healthcare professionals in the use and management of e-health systems. Major in-house training on e-health is usually carried out in developed countries but less in developing countries. Although e-health systems are expected to be extremely user-friendly, technical assistance, and guides for the use of the systems are to be provided. Training on the use of social media and health systems can also improve the potential benefits of e-health.

[48] Suggested training and e-health education for hospital staff and health care professionals so they can visualize the benefits of e-health solutions and in turn, push the success of these innovations. Also, the study proposes a model involving the use of open source e-health software, development, and improvement of infrastructures by the government and the establishment of documented e-health policies that support the growth of e-health education. [49] Emphasized the need for an increase in e-health awareness and sensitizations through seminars and training workshops for health professionals as well as an increase in electronic communications. Also, developing guidance on the use of the technologies, medical device labeling and event reporting systems for the devices are recommended to improve usability and effectiveness in developing countries.

\subsection{Evidence-based evaluations}

The growth of e-health adoption can be accelerated with the provision of reliable evidence provided through evaluation of the e-health technologies implemented and outcome on health. This could, in turn, facilitates the trustworthiness and reliability of the intervention. Evaluations are expected to focus on the success or failure of ehealth and considerably fosters the long-term sustainability of e-health. Developing countries need to have a framework in place where it is possible to access the impact of e-health and this can serve as a catalyst to further investment.

[50] Proposed an iterative approach (involving users in all stages of the development of the technologies), formal and usage over time evaluations techniques. Some mixed methods that involve the use of questionnaires, scenario-based evaluations, usability testing, and logging and video recording of sessions are suggested as well. [51] Also suggested two evaluation techniques, cost-benefit analysis (CBA) and costeffectiveness analysis (CEA). The CBA values the health outcome and benefits in monetary terms and the CEA identifies what benefits can be realized at a lower cost.

\subsection{Open E-health standard and national health policy}

The various fundamentals of e-health standards are to be set out as a plan of action in the delivery of health services. Countries with set out e-health policies have better health services and usually attract public funding. These policies guide the e-health 
programmes, foster strategic large-scale implementation and address the contributions of e-health to health objectives. Developing countries need regulations and standards that ensure quality, safety, and reliability of health applications. Mobile e-health applications particularly require privacy policies which may vary in different countries thereby affecting their scalability. Creating the e-health national standards streamlines healthcare causing a more efficient e-health system. The monopoly of health facilities can also limit e-health coverage therefore, an open standard will also ensure that genuine fragmented systems in the market can be reconfigured to connect, conform and interoperate with national e-health facilities. [52] Recommended that the government provide policies and regulations that outline the standards and criteria that national e-Health strategies must meet to be certified. Trained health care professionals should be monitored through continuous professional developments and their skills should be tested through examinable curriculums. They also highlighted the need for a regulatory body and subcommittee to examine e-health interventions with national awareness. It is also advised that there should be the implementation of regulated compulsory use of e-health systems policies at all times.

\subsection{Global connectivity to local, regional and international stakeholders}

Collaborative efforts and communication between diverse stakeholders can increase the creation of innovative approaches in solving e-health challenges in developing countries. These stakeholders include the ministries of health and finance, public and private healthcare institutions, research organizations, professional bodies, and local and international partners. Their commitment is essential to the development of health-workforce and health care coverage. Global connectivity has been proven to work in developed countries and some developing regions like the ASEAN have started adopting this. Neighboring countries in Africa can also collaborate and partner on cross border access of e-health infrastructure. This will help to improve the ubiquitous healthcare process at a low cost.

\subsection{Multilingual framework}

E-health services provided to citizens in the language they speak will encourage the adoption of the e-health initiative. Technologies that provide multilingual support are more engaging and user-friendly, thereby promoting understanding and connectivity to both health staff and patients. A national policy that promotes linguistic diversity and multilingual e-health content will enhance e-health adoption. This has been reported to be one of the least explored features of e-health despite being capable of raising the level of awareness and adoption in developing countries.

\section{Conclusion}

Some of the challenges faced by e-health strategies in Africa include insufficient skilled health care workers, lack of health information systems, shortage of drugs, 
inadequate public information and financial constraints. ICT has proven to be very useful in several sectors of the world's economy like government, manufacturing, banking and so on. The use of computers and technologies have helped to improve productivity, efficiency, coverage, and availability of various services at reduced cost. ICT in health, also known as e-health, is also becoming one of the widely recognized areas of application of technologies in the modern world. Transitioning healthcare systems in Africa and other developing countries, where budget and funds for health is very low, is challenging. In this work, we carried out a review of some e-health systems and strategies in Africa and some other developing countries. And it was found, that though e-health and other related technologies are gaining some momentum in developing countries, there is still need for further improvement. We, therefore, proposed a framework for sustainable e-health system based on the gaps identified in the reviewed works. This work is expected to contribute to the development of long-term e-health implementation in developing countries.

\section{$5 \quad$ References}

[1] Peters, D. H., Garg, A., Bloom, G., Walker, D. G., Brieger, W. R., \& Rahman, M. H. (2008). Poverty and access to health care in developing countries. Annals of the New York Academy of Sciences, 1136(1): 161-171 https://doi.org/10.1196/annals.1425.011

[2] Omotosho, A., Emuoyibofarhe, J., Ayegba, P. \& Meinel, C. (2019). E-Prescription in Nigeria: A Survey. Journal of Global Pharma Technology, 10(12S): 58 - 64

[3] World Health Organization (2016). Global Diffusion of eHealth: Making Universal Health Coverage Achievable. Report of the Third Global Survey on eHealth. Geneva, Switzerland.

[4] Sen, A. (1992). Inequality Reexamined. Cambridge, Mass: Harvard University Press.

[5] Ravishankar, N., Gubbins, P., Cooley, R. J., Leach-Kemon, K., Michaud, C. M., Jamison, D. T., \& Murray, C. J. (2009). Financing of global health: tracking development assistance for health from 1990 to 2007. The Lancet, 373(9681): 2113-2124 https://doi.org/10.1016/ s0140-6736(09)60881-3

[6] E-transform Africa (2012), ICTs for health in Africa. Available at http://siteresources.worldbank.org/EXTINFORMATIONANDCOMMUNICATIONANDT ECHNOLOGIES/Resources/282822-1346223280837/Health.pdf

[7] The Sun (2017), Nigeria's poor healthcare access ranking. Available at https://www.sunnewsonline.com/nigerias-poor-healthcare-access-ranking/

[8] Olawale G. \&Orogun G. (2017). One doctor still attends to 6,000 patients in Nigeria-Don. Available at https://www.vanguardngr.com/2017/01/one-doctor-still-attends-6000patients-nigeria-don/

[9] Bresnahan, T. F., \&Trajtenberg, M. (1995). General purpose technologies 'Engines of growth'? Journal of econometrics, 65(1): 83-108 https://doi.org/10.1016/0304-4076(94) 01598-t

[10] Dinya E. \& Toth T. (2013), Health Informatics: eHEALTH and TELEMEDICINE, Presentation, Semmelweis University.

[11] Frost \& Sullivan (2016). Enabling eHealth technology in South Africa, Kenya \& Ghana: Accelerating healthcare with mHealth, Healthcare IT and Telemedicine. Available at: http://www.frost.com/sublib/display-report.do? 
[12] Omotosho, A., Asani, E. O, Ogundokun, R.O, Ananti E. C., \&Adegun A. (2018). A NeuroFuzzy Based System for the Classification of Cells as Cancerous or Non-Cancerous. International Journal of Medical Research \& Health Sciences, 7(5):155-166

[13] Omotosho, A., Emuoyibofarhe, J., \& Meinel, C. (2017). Ensuring patients' privacy in acryptographic-based-ehr using bio-cryptography. International Journal of Electronic Healthcare (IJEH), 9(4): 227 - 254 https://doi.org/10.1504/ijeh.2017.085800

[14] Omotosho, A., Asanga, U., \&Fakorede, A. (2017). Electronic Prescription System for Pediatricians. European Scientific Journal, 13(18): 426 - 437 https://doi.org/10.19044/esj. 2017.v13n18p426

[15] Omotosho, A., Adegbola, O., \&Adebo, A. (2016). A Patient-Based Hospital Referral Decision Support System. International Journal of Computer Application, 115(10): 38 - 43 https://doi.org/10.5120/ijca2016912459

[16] Qureshi, N. A., Kundi, G. M., Qureshi, Q. A., Akhtar, R., \& Hussain, L. (2015). An investigation into the adoption and use issues of E-health in public sector hospitals of developing countries. Mediterranean Journal of Medical Sciences, 2(1): $23-36$

[17] Kip, H., Bouman, Y. H., Kelders, S. M., \& van Gemert-Pijnen, L. J. (2018). eHealth in treatment of Offenders in Forensic mental Health: A Review of the current State. Frontiers in psychiatry, 9(42): 1 - 19 https://doi.org/10.3389/fpsyt.2018.00042

[18] Blaya, J. A., Fraser, H. S., \& Holt, B. (2010). E-health technologies show promise in developing countries. Health Affairs, 29(2): 244-251 https://doi.org/10.1377/hlthaff.2009. $\underline{0894}$

[19] Gemert-Pijnen, J. E., Nijland, N., van Limburg, M., Ossebaard, H. C., Kelders, S. M., Eysenbach, G., \& Seydel, E. R. (2011). A holistic framework to improve the uptake and impact of eHealth technologies. Journal of medical Internet research, 13(4). https://doi. org/10.2196/jmir.1672

[20] Shiferaw, F., \& Zolfo, M. (2012). The role of information communication technology (ICT) towards universal health coverage: the first steps of a telemedicine project in Ethiopia. Global health action, 5(1): 15638 https://doi.org/10.3402/gha.v5i0.15638

[21] Holanda, A. A., Do Carmo e Sá, H. L. D. C., Vieira, A. P. G. F., \&Catrib, A. M. F. (2012). Use and satisfaction with electronic health record by primary care physicians in a health district in Brazil. Journal of medical systems, 36(5): 3141-3149 https://doi.org/10.1007/ s10916-011-9801-3

[22] Sukums, F. K. (2016). Implementation of an electronic clinical decision support system for maternal care in rural primary health care facilities in Ghana and Tanzania: Assessment of its adoption and usability.

[23] Betjeman, T. J., Soghoian, S. E., \& Foran, M. P. (2013). mHealth in sub-Saharan Africa. International journal of telemedicine and applications. https://doi.org/10.1155/2013/ 482324

[24] Cohen, J. F., Coleman, E., \& Abrahams, L. (2015, May). Use and Impacts of E-health Within Community Health Facilities in Developing Countries: A Systematic Literature Review. In ECIS 2015 Completed Research Papers. Paper 33.

[25] Brinkel, J., Dako-Gyeke, P., Krämer, A., May, J., \&Fobil, J. N. (2017). An investigation of users' attitudes, requirements and willingness to use mobile phone-based interactive voice response systems for seeking healthcare in Ghana: a qualitative study. public health, 144: 125-133 https://doi.org/10.1016/i.puhe.2016.11.017

[26] Hoque, M. R., Bao, Y., \& Sorwar, G. (2017). Investigating factors influencing the adoption of e-Health in developing countries: A patient's perspective. Informatics for Health and Social Care, 42(1): 1-17 https://doi.org/10.3109/17538157.2015.1075541 
[27] Mars, M. (2013). Telemedicine and advances in urban and rural healthcare delivery in Africa. Progress in cardiovascular diseases, 56(3): 326-335 https://doi.org/10.1016/j. pcad.2013.10.006

[28] Nyamtema, A., Mwakatundu, N., Dominico, S., Kasanga, M., Jamadini, F., Maokola, K., Mawala, D., Abel, Z., \& Van Roosmalen, J. (2017). Introducing eHealth strategies to enhance maternal and perinatal health care in rural Tanzania. Maternal health, neonatology and perinatology, 3(1): 3 https://doi.org/10.1186/s40748-017-0042-4

[29] Boore, C., James, N. M., \&Iraki, X. N. (2017). Strategic issues in e-Health implementation in developing countries: The Kenyan healthcare sector. Global Scientific Journals, 5(7): 50 $-62$

[30] Ekanoye, F., Ayeni, F., Olokunde, T., Nina, V., Donalds, C., \&Mbarika, V. (2017). Telemedicine Diffusion in a Developing Country: A Case of Nigeria. Science Journal of Public Health, 5(4): 341 - 346

[31] Vu, K. M. (2017). ICT diffusion and production in ASEAN countries: Patterns, performance, and policy directions. Telecommunications Policy, 41(10): 962-977 https://doi. org/10.1016/j.telpol.2017.04.005

[32] Bloom, G., Berdou, E., Standing, H., Guo, Z., \&Labrique, A. (2017). ICTs and the challenge of health system transition in low and middle-income countries. Globalization and health, 13(1): 56 https://doi.org/10.1186/s12992-017-0276-y

[33] Ebenso, B., Allsop, M. J., Okusanya, B., Akaba, G., Tukur, J., Okunade, K., Akeju, D., Ajepe, A., Dirisu, O., Yalma, R., Sadeeq, A. I., Okuzu, O., Ors, T., Jagger, T., Hicks, J.P., Mirzoev T. \& Newell, J.N. (2018). Impact of using eHealth tools to extend health services to rural areas of Nigeria: protocol for a mixed-method, non-randomised cluster trial. BMJ open, 8(10): e022174 https://doi.org/10.1136/bmjopen-2018-022174

[34] Alunyu, A. E., \& Nabukenya, J. (2018). A Conceptual Model for Adaptation of eHealth Standards by Low and Middle-Income Countries. Journal of Health Informatics in Africa, $5(2)$.

[35] Al-Shorbaji, N., Househ, M., Taweel, A., Alanizi, A., Mohammed, B. O., Abazae, H., Bawadif,H., Rasulyg,H., Alyafeih, K., Luquei, L.F., Shoumanj, M., El-Hassank, O., Husseinl, R., Alshammarim, R., Mandiln, S., Shoumanj, S., Taherio, S., Emaraj, T., Dalhemp, W., Al-Hamdanq, Z., Serhierr, Z. (2018). Middle East and North African Health Informatics Association (MENAHIA): Building Sustainable Collaboration. Yearbook of medical informatics. https://doi.org/10.1055/s-0038-1641207

[36] Hossain, N., Sampa, M. B., Yokota, F., Fukuda, A., \& Ahmed, A. (2018). Factors Affecting Rural Patients' Primary Compliance with e-Prescription: A Developing Country Perspective. Telemedicine and e-Health. https://doi.org/10.1089/tmj.2018.0081

[37] Paton, C. and Muinga, N. (2018). Electronic Health Records: a case study from Kenya. Pathways for Prosperity Commission Background Paper Series; no. 12. Oxford, United Kingdom.

[38] Furusa, S.S. \& Coleman, A., 2018, 'Factors influencing e-health implementation by medical doctors in public hospitals in Zimbabwe'. South African Journal of Information Management, 20(1): a928. https://doi.org/10.4102/sajim.v20i1.928

[39] Ladan, M. A., Wharrad, H., \& Windle, R. (2018). Uncovering a tripartite relationship between patient, eHealth and healthcare professionals.

[40] Gerber, T., Olazabal, V., Brown, K., \&Pablos-Mendez, A. (2010). An agenda for action on global e-health. Health affairs, 29(2): 233-236 https://doi.org/10.1377/hlthaff.2009.0934

[41] Mauco, K. L., Scott, R. E., \& Mars, M. (2018). Critical analysis of e-health readiness assessment frameworks: suitability for application in developing countries. Journal of telemedicine and telecare, 24(2): 110-117 https://doi.org/10.1177/1357633x16686548 
[42] Le Pape, M. A., Suárez, J. C. N., Mhayi, A., Haazen, D., \&Özaltin, E. (2017). Developing an HMIS Architecture Framework to Support a National Health Care eHealth Strategy Reform: A Case Study from Morocco. Health Systems \& Reform, 3(1): 56-67 https://doi.org/ $\underline{10.1080 / 23288604.2017 .1265041}$

[43] Kiberu, V. M., Mars, M., \& Scott, R. E. (2017). Barriers and opportunities to implementation of sustainable e-Health programmes in Uganda: A literature review. African journal of primary health care \& family medicine, 9(1): 1-10 https://doi.org/10.4102/phcfm.v9i1. $\underline{1277}$

[44] Harding, K., Biks, G. A., Adefris, M., Loehr, J., Gashaye, K. T., Tilahun, B., ...\&Mersha, T. B. (2018). A mobile health model supporting Ethiopia's eHealth strategy. Digital Medicine, 4(2): 54 https://doi.org/10.4103/digm.digm 10_18

[45] Muinga, N., Magare, S., Monda, J., Kamau, O., Houston, S., Fraser, H., Powell, J., English, M., Paton, C. (2018). Implementing an open source electronic health record system in Kenyan health care facilities: Case study. JMIR medical informatics, 6(2). https://doi.org/ $10.2196 /$ preprints. 8403

[46] Dobrev, A., Stroetmann, V., Stroetmann, K., Artmann, J., Kersting, A., Kasiri, N., Zegners, D., \&Lilischkis, S., (2008) Sources of financing and policy recommendations to Member States and the European Commission on boosting eHealth investment. Final report of the Financing eHealth study. Available at: http://www.financingehealth.eu/downloads/documents/FeH_D5_3_final_study_report.pdf https://doi.org/10.4414/smi.26.00212

[47] Basher, M.A. \& Roy, P.C. (2011). Introducing an e-Health card for Developing Countries: A case study of Bangladesh. Master Thesis, Stockholm University, Sweden., p. 38

[48] Ouma, S., \&Herselman, M. E. (2008). E-health in rural areas: case of developing countries. International Journal of Biological and Life Sciences, 4(4): 194-200

[49] Abodunrin, O., \& Akande, T. (2009). Knowledge and perception of e-health and telemedicine among health professionals in LAUTECH teaching hospital, Osogbo, Nigeria. International Journal of Health Research, 2(1): 51-58 https://doi.org/10.4314/ijhr.v2i1.55388

[50] Kulyk, O. (2014). How to evaluate the success of technology-based interventions. Available at: https://www.utwente.nl/en/bms/ehealth/documents/workshop-2014/workshopehealth-icbm2014-evaluation-methods-o.kulyk.pdf

[51] Bergmo, T. S. (2015). How to measure costs and benefits of eHealth interventions: an overview of methods and frameworks. Journal of medical Internet research, 17(11). https:// doi.org/10.2196/jmir.4521

[52] Gregory, M., \&Tembo, S. (2017). Implementation of E-health in Developing Countries Challenges and Opportunities: A Case of Zambia. Science and Technology, 7(2): 41-53

\section{Authors}

Adebayo Omotosho is currently a visiting research in Internet Technologies and System Group at Hasso Plattner Institute, University of Potsdam, Germany. He is alsoa lecturerin the Department of Computer Science, Landmark University, OmuAran. He received his Ph.D. in Computer Science at Ladoke Akintola University of Technology in 2016. He is a Seasoned Computer Programmer and has taken part in a number of programming competitions in $\mathrm{C} / \mathrm{C}++/ \mathrm{C} \#$. He is a member of the Nigeria Computer Society (NCS), Computer Professional [Registration Council] of Nigeria 
(CPN), Computer Science Teachers Association for Computing Machinery (ACM), and International Association of Computer Science and Information Technology. His research interests are health informatics, computer security, machine learning, and biometrics.

Peace Ayegba is a research assistant in the Department of Computer Science, Landmark University Omu-Aran. She is currently on her M Sc degree and her research areas are computer security, human-computer interaction and artificial intelligence.

Justice Emuoyibofarhe is a Professor of Computing at the Ladoke Akintola University of Technology. He received his Ph.D. in 2004. He specializes in neuro-fuzzy computing computational optimization. He had post-doctoral fellowship at the Centre of Excellence for Mobile e-service, University of Zululand, South Africa in 2006. He is a member of the IEEE Computational Intelligence Society. He is also a Visiting Researcher at the Hasso Plattner Institute, University of Potsdam, Germany. His present research area is in the application of mobile computing and wireless communication to e-health and telemedicine.

Christoph Meinel is a German Scientist and a University Professor of Computer Sciences. He is President and CEO of the Hasso Plattner Institute (HPI) for IT Systems Engineering at the University of Potsdam (Germany), and a Professor for Internet Technologies and Systems. Besides his teaching activities in Potsdam, he is an Honorary Professor at the Technical University of Beijing (China), a Visiting Professor at the Shanghai University (China), and a Senior Research Fellow of SnT at the University of Luxembourg. He is a Chairman or a member of various international scientific boards and program committees and has organized several internal symposia and conferences

Article submitted 2019-02-09. Resubmitted 2019-03-27. Final acceptance 2019-03-28. Final version published as submitted by the authors. 